\title{
4
}

\section{A Methodology to Design and/or Assess Baffles for Floatables Control}

Thomas L. Newman II

This chapter describes an analytical framework for the design and/or analysis of baffles to reduce floatables discharges from combined-sewer overflows (CSOs). This simple analytical framework, which is supported with a spreadsheet model, is compared to its predecessors and its advantages illustrated. These include ease of use, improved applicability to typical installation configurations, and refined analyses of floatables-removal mechanisms. Refined analyses include a simple accounting for flow path through a chamber - including a provision for situations where the invert of the inlet conduit is at a higher elevation than the bottom of the baffle - and a simple accounting for floatables capture via the underflow (dry-weather connection) during overflow conditions. Results of the model are compared to the results of the previous approaches and to available laboratory test data for four test cases. Examples of the model application to cases in the City of New York are available from the author. Finally, possible areas for future improvement in the model approach are identified.

\subsection{Introduction}

Interest in methods to reduce discharges of floatables from municipal combined-sewer systems has become widespread in the wake of a regulatory focus on controlling pollutant discharges from combined-sewer overflows (USEPA, 1995). Seeking to comply with regulatory guidelines, municipalities have

Newman, T. 2001. "A Methodology to Design and/or Assess Baffles for Floatables Control." Journal of Water Management Modeling R207-04. doi: 10.14796/JWMM.R207-04.

(C) CHI 2001 www.chijournal.org ISSN: 2292-6062 (Formerly in Models and applications to Urban Water Systems. ISBN: 0-9683681-4-X) 
sought cost-effective control alternatives. Baffles (Figure 4.1) are among the more attractive floatables-control alternatives. Although widely used to enhance separation processes for settleable solids, scum and oils, baffle technology has not been widely applied to control combined-sewer floatables. When properly installed in a combined-sewer regulator structure, a baffle traps floatables on its upstream side and detains them there until the storm subsides, when they are conveyed to the treatment facility along with the dry-weather flow.

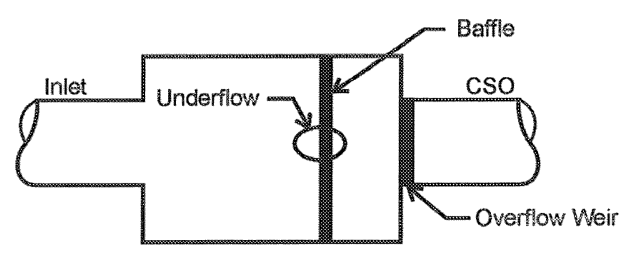

Plan

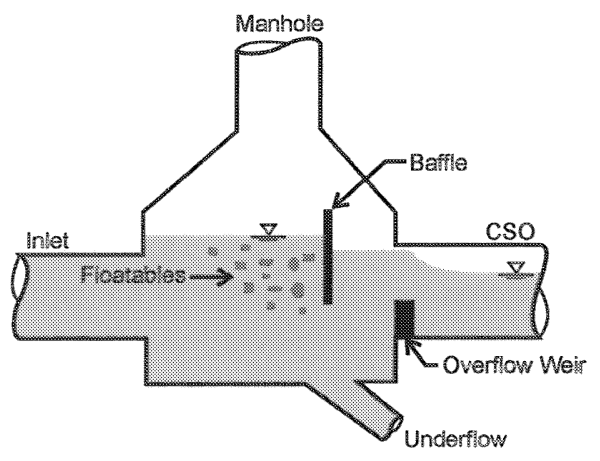

Section

Figure 4.1 Combined-sewer regulator with baffle.

Baffles are among the least expensive of floatables-control alternatives (Heath et al., 1996; Walker et al., 1998a) and have widespread application thanks to their relatively simple design, easy installation in existing regulator structures, and suitability for use in conjunction with other controls. The available evidence demonstrating baffle effectiveness has been limited primarily to laboratory experiments (White and Larsen,1997; Walker et al., 1998a; Cigana et al., 1998b; Cigana et al., 1998c), which have been positive for some conditions and less so for other conditions. Evidence demonstrating baffle effectiveness in field applications has been sparse (Cigana et al., 1998a), and guidance for baffle design has been limited (Dalkir et al., 1996; Metcalf \& Eddy, 
1996; Furrier, 1998; Cigana et al., 1998b, Cigana et al., 1998c), particularly with respect to analysis of expected floatables-removal efficiency.

Two recent project assignments required the author to propose conceptual designs to retrofit existing regulator structures with baffles, and to develop quantitative assessments of the expected floatables-removal efficiency of these proposed installations. The few analytical frameworks found in the literature had shortcomings when applied to many typical regulator configurations. To address these shortcomings, the author developed a more refined analytical approach, applied in a useful spreadsheet format. This spreadsheet model features three principal improvements over its predecessors. First, it accounts for vertical variations in the flow path between the regulator inlet and outlets (as described in Section 4.4.2). Previous approaches often predicted optimistic removal efficiencies because vertical variations in the flow path were not accounted for. Second, this model accounts for the floatables captured in the regulator outlet to the interceptor, and distinguishes between these floatables and those retained by the baffle until the end of the storm. This innovation is especially useful because it allows the user to simulate the pre-baffle condition and thereby determine the net improvement in floatables capture that the baffle affords. Third, the spreadsheet format enables the user to easily identify the relative importance of the various design elements when optimizing floatablesremoval efficiency for a particular installation.

Of course, designing a baffle retrofit requires consideration of many issues other than the floatables-removal efficiency. These issues include establishing a design condition (e.g. rainfall and tidal conditions), velocity changes, headloss changes, baffle composition, ease of installation, consequence of failure, and access for maintenance. This chapter focuses on the analysis of the floatables-removal efficiency.

\subsection{Literature Review}

In its CSO Control Policy Nine Minimum Controls (USEPA, 1995), the USEPA cites baffles as a candidate technology to control floatables discharges from CSOs. Baffles are simple, inexpensive, easily installed in existing combinedsewer-system structures, and have no power or special maintenance requirements. However, experience with baffles for CS floatables control is lacking, and information demonstrating the ability of baffles to remove floatables has been sparse. As a result, what little information is available to provide guidance into baffle design for floatables control is not yet field tested. This section summarizes information from the literature that relates to the use of baffles for CS floatables control. 


\subsubsection{Testing of Baffles for Floatables Control}

The author is aware of only two studies that measured the ability of baffles to capture combined-sewer floatables. The results of these studies are briefly summarized below.

The first study (White and Larsen, 1997; Walker et al., 1998a; Walker et al., 1998b), performed by Alden Research Laboratories at the direction of the Massachusetts Water Resources Authority (MWRA), involved hydraulic testing with a scaled physical model of a typical Boston regulator chamber. The transformed chamber dimensions were $3.05 \mathrm{~m}$ long by $2.44 \mathrm{~m}$ wide with one $1.22 \mathrm{~m}$ diameter inlet conduit, a $0.46 \mathrm{~m}$ diameter dry-weather flow conduit, and a $0.91 \mathrm{~m}$ diameter overflow conduit. Using floatable items selected to mimic the most typical items found in New York City CSOs (as reported by HydroQual, Inc., 1993), Alden Laboratories evaluated floatables capture for a number of baffle configurations and flow conditions ranging from 0.255 to 0.85 $\mathrm{m}^{3} / \mathrm{s}$ (inlet) and 0.023 to $0.77 \mathrm{~m}^{3} / \mathrm{s}$ (overflow).

In general, the results of the Alden Laboratory tests indicated that a simple, single-baffle configuration could remove anywhere from $38 \%$ to $94 \%$ of CS floatables (item-count basis), depending upon the flow conditions. In general, more buoyant items, such as polystyrene pieces, were more readily captured than less buoyant items, such as plastic bags and cigarette butts. It was also observed that if the baffle extended too close to the regulator invert, the increased under-baffle velocities tended to carry floatables under the baffle, thereby reducing baffle effectiveness. Tests with other baffle configurations showed that some (but not all) multiple-baffle configurations helped to reduce this carry-under loss of floatables. One triple-baffle design improved removal efficiency to between $51 \%$ and nearly $100 \%$ (again, on an item-count basis), depending upon the flow conditions. Additional results of this study are discussed in Section 4.4.

The second study (Cigana et al., 1998b; Cigana et al., 1998c) was performed by John Meunier, Inc. at the Ecole Polytechnique of Montreal. These tests were performed in a $17 \mathrm{~m}$ long, $1 \mathrm{~m}$ wide channel with flow velocities ranging from 0.2 to $1.4 \mathrm{~m} / \mathrm{s}$. Floatable items were selected to mimic typical items found in Montreal CSOs (as reported by Paradis et al., 1996). Floatablesremoval efficiencies were tested on an item-count basis for single-baffle configurations with under-baffle clearance varying from $85 \%$ down to $50 \%$ of the $1 \mathrm{~m}$ pre-baffle flow depth.

The findings of the Meunier study were less positive than the Alden Laboratories study. Results of these tests indicated that moderate under-baffle velocities significantly reduce baffle effectiveness. Although floatables- 
removal efficiencies at low horizontal flow velocity $(0.2 \mathrm{~m} / \mathrm{s})$ ranged from about $45 \%$ to near $80 \%$ (item-count basis) for shallow and deep baffles, respectively, performance quickly deteriorated with increasing horizontal flow velocity. Regardless of baffle depth, floatables-removal efficiency dropped to less than $10 \%$ (item-count basis) when horizontal flow velocities exceeded about $0.35 \mathrm{~m} / \mathrm{s}$.

\subsubsection{Floatables Characteristics}

There have been several studies over the last decade that report general characteristics of floatables. (HydroQual, 1992; HydroQual, 1993; HydroQual, 1995; St. John et al., 1994; Turner, 1995; Paradis et al., 1996; Crane and Davidson, 1998; Cigana et al., 1999; Allison, 1999). Typically, these studies indicate the relative composition of the materials and/or specific item types found on city streets, in sewer systems, in CSOs, on open waters, and/or in beach washups. The author has recently developed a comparison of information regarding floatables composition in New York and other cities (Newman et al., 2000).

As indicated above, the physical characteristics of a floatable item, particularly the characteristic rise velocity of the item, is of primary importance regarding whether a baffle will capture the item. Unfortunately, there are limited sources of information pertaining to the rise-velocity characteristics of floatables. Laboratory studies conducted on New York City floatables in 1993 and 1999 (Newman et al., 2000) have provided still-water, rise-velocity data for approximately 40 litter items corresponding to some of the most common items discharged from combined sewers.

Meanwhile, other investigators analyzed the composition and rise-velocity characteristics of floatables taken from two CSOs in the Montreal area (Paradis et al., 1996; Cigana et al., 1999). The rise-velocity experiments were conducted in both still-water and turbulent-flow environments. A particularly useful product of these experiments is a probability distribution of rise velocities for CSO floatables reflecting still-water measurements on over 2,000 items (Figure 4.2). This probability distribution relates the percentage of CSO floatables that have rise velocities of at least the given magnitude. For example, approximately $20 \%$ of CSO floatables have rise velocities of at least $10 \mathrm{~cm} / \mathrm{s}$. However, this probability distribution reflects the two Montreal outfalls and may or may not be representative of CSO floatables from other areas or for different seasons. Indeed, qualitative descriptions of the floatables retrieved from those tests indicate a preponderance of vegetative and organic food-waste materials not typically found in New York City CSOs. 


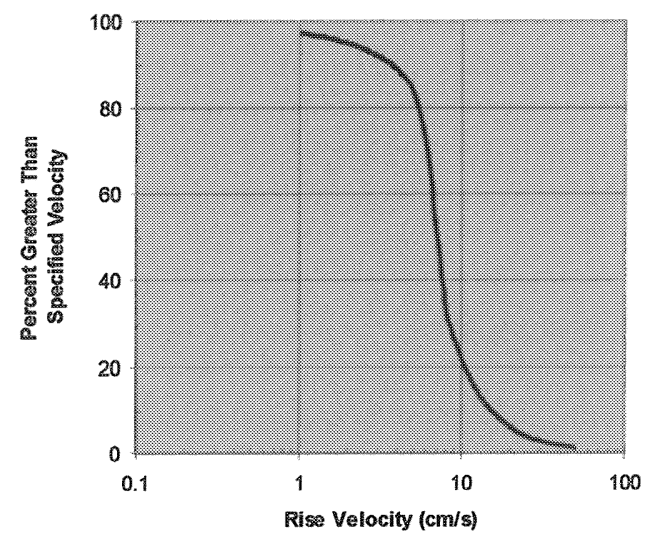

Figure 4.2 Rise-velocity distribution, Montreal CSO floatables.

\subsubsection{General Guidelines to Improve Baffle Performance}

In addition to the Alden Laboratories study, several investigations reported by CEGEO Technologies, Inc., John Meunier, Inc., and the Ecole Polytechnique of Montreal present some general suggestions for improving floatables removal with baffles. In one of these investigations (Dalkir et al., 1996), a host of recommendations are given that are purported to enhance baffle performance. These recommendations include the following:

1. to reduce headloss and minimize turbulence, the chamber in which the floatables are to rise should be rectilinear, with gradual changes to structural geometry at the entrance and exit points, and the walls of the chamber should be as smooth as possible;

2. flow within the chamber should not change direction upstream of the overflow weir, which, like the baffle, should be oriented perpendicularly to the flow direction;

3. flow should be spread out uniformly and symmetrically over the entire width of the chamber;

4. the chamber overflow weir should be constructed as high as possible without causing upstream flooding; the hydraulic efficiency of the weir would be improved by giving the weir an ogee profile and adding a metal plate along the top for a sharp crest;

5. local velocities around the bottom edge of the baffle should be minimized, preferably to less than $1 \mathrm{~m} / \mathrm{s}$, to reduce the carryunder loss of floatables under the baffle;

6. the bottom edge of the baffle should be at least $15 \mathrm{~cm}$ below the crest of the overflow weir; 
7. the top edge of the baffle should allow passage over the baffle for flows exceeding the design condition, while extending at least 15 $\mathrm{cm}$ above the maximum water elevation at the design flow condition, and the height of the baffle over the overflow weir crest should be at least 1.25 times the maximum head at the design flow condition.

As part of work conducted for MWRA, Metcalf and Eddy, Inc. performed limited hydraulic computer modeling and best professional judgment to develop guidelines for baffle design. These suggestions and guidelines (Walker et al., $1998 \mathrm{~b})$ include guidance for baffle placement $(0.38 \mathrm{~m}$ minimum between bottom edge of baffle and crest of overflow weir, $0.30 \mathrm{~m}$ minimum clearance behind and under baffle, and $0.15 \mathrm{~m}$ minimum extension above design watersurface elevation) and limits on the allowable under-baffle velocity $(1.52 \mathrm{~m} / \mathrm{s})$. As part of the same study for MWRA, Camp Dresser and McKee, Inc. also developed guidelines for baffle design (Furrier, 1998). Furrier adopted many of Walker's suggestions and also recommended a procedure to facilitate baffle placement.

\subsubsection{Analytical Approaches to Assess Floatables-Removal Efficiency}

Over the past few years, several studies have presented analytical approaches to assess floatables capture in a baffled channel (Dalkir et al., 1996; Cigana et al., 1998b; Cigana et al., 1998c). These approaches involve methods to estimate the minimum rise velocity necessary for a floatable item to intercept the baffle when released from a given location upstream of the baffle. This section briefly introduces the existing approaches, which are described in more detail in Section 4.3.

Citing theory previously applied to settleable solids, Dalkir first presented an analytical approach whereby a baffle placed into the flow captures floatable items whose rise trajectories intercept it. Rise trajectories are calculated based upon the physical dimensions of the channel and baffle, the flow velocity, the item rise velocity, and the turbulence of the flow. The overall floatablesremoval efficiency for the baffle installation is then estimated by comparing the minimum rise velocity that can intercept the baffle to the probability distribution of rise velocities for typical combined-sewer floatables (such as shown on Figure 4.2). This methodology is illustrated in Section 4.3.2.

In a follow-up to Dalkir's work, Cigana adopted a similar approach, but suggested an alternate, experimentally based method to account for turbulent effects on rise velocity. This methodology, which relates the effective rise velocity under turbulent conditions to the rise velocity observed under stillwater conditions, is illustrated in Section 4.3.2. 
Dalkir and Cigana also suggest another approach that defines the critical conditions necessary to effect an $80 \%$ floatables-removal efficiency. This approach may be useful for baffle design in new-construction applications; however, it has not yet been developed to the point where it is useful to calculate the expected floatables capture from a baffle retrofit in an existing chamber.

\subsection{Analysis of Baffles for Floatables-Removal Efficiency}

An analytical approach to estimate the floatables-removal efficiency of a proposed baffle installation is an important element in the evaluation of whether the baffle should be installed in one location or another, or whether the baffle will perform more cost-effectively than other control technologies.

\subsubsection{Overview and General Considerations of Baffle Performance}

A CS system conveys both sanitary sewage and, during wet weather, rainfall runoff to a treatment facility. However, few treatment facilities can accommodate the high volumes of flow associated with larger rainfall events, and CS systems typically have relief points or regulators to limit the amount of flow conveyed to the treatment facility.

As shown in Figure 4.1, a typical regulator is a chamber that is somewhat larger in cross-sectional area than the pipes it intersects. It consists of one or more inlets; an underflow connection to convey flow to the treatment facility; and an overflow conduit to route excess flow to another location, such as a receiving water. A static overflow weir, located either in the regulator chamber or at the entrance to the overflow conduit, diverts all flow to the underflow connection during dry weather. During wet weather, the water-surface elevation rises and may overtop the weir to produce a CSO.

Turbulence and mixing in the inlet conduit generally keeps the inflow well mixed. For purposes of analysis, it is conservative to assume that the influent floatables are well mixed with depth and that any separation does not occur until the flow enters the regulator chamber. Once the flow enters the regulator chamber, velocities decrease and the inherently buoyant floatable materials tend to rise toward the surface. During CSO periods, these floatables can discharge freely over the weir. Placing a baffle into the flow tends to trap these floatables on the upstream side of the baffle. When the water level subsides, the accumulated floatables cannot exit the regulator via the CSO if the bottom edge 
of the baffle is lower than the top of the overflow weir. Instead, these floatables drain to the underflow connection, which conveys them to the treatment facility.

Baffle performance is a function of the buoyancy of the influent floatables as well as the hydraulics in the regulator chamber. Hydraulics here refers to the flow pathways (or streamlines) from the inlet to the outlets (Figure 4.3), the velocity of the flow along these streamlines, and the flow turbulence, which tends to mix flow among adjacent streamlines.

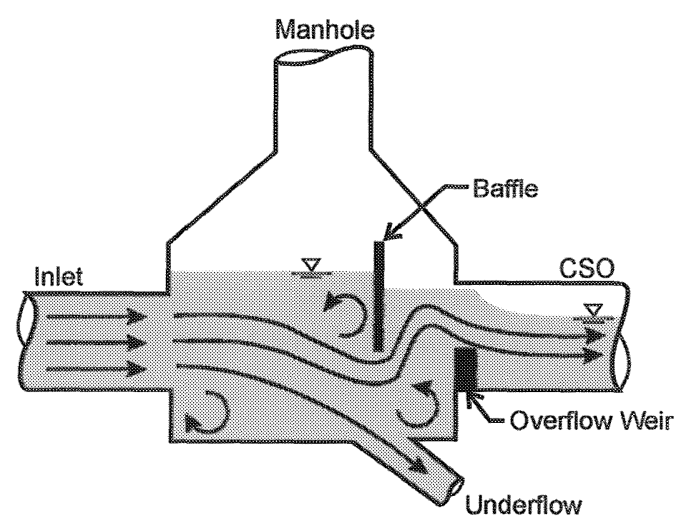

Figure 4.3 Streamlines in a baffled regulator.

In the absence of turbulence, neutrally buoyant items follow one streamline through the chamber from inlet to outlet. Positively buoyant items, on the other hand, tend to climb from one streamline to the next as they flow through the chamber, and their resultant trajectories are a function of their individual rise velocities as well as the velocities of the streamlines carrying them. In real situations, turbulent mixing can superimpose an almost random vertical pattern on the item's trajectory, with the net result typically inhibiting the item's ability to rise (Figure 4.4). Turbulence and mixing within the regulator chamber can also cause previously trapped floatables to become re-entrained in streamlines that carry the items to the CSO. Conversely, eddies and dead zones can trap floatables in the regulator even without the physical barrier of a baffle.

In general, it is self-evident that floatables capture in a baffled chamber should increase for more buoyant items and for hydraulic conditions that provide longer available rise times within the chamber. The important factors affecting the floatables-removal efficiency of a baffle installation include the dimensions of the regulator chamber, the orientation of the baffle relative to the 


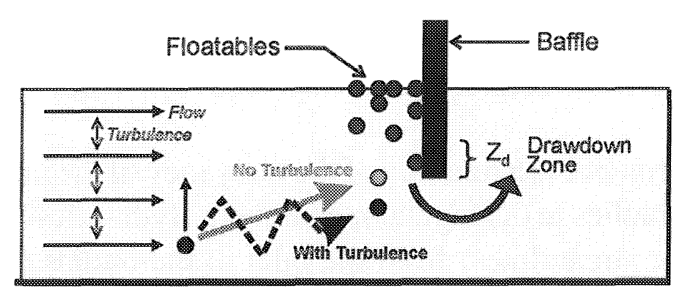

Section

Figure 4.4 Effect of turbulence on rise velocity.

inlets and outlets, the relative proportion of the flow captured in the underflow versus discharged via the $\mathrm{CSO}$, the flow velocities within the regulator chamber, the turbulence and mixing in the chamber, and the characteristic rise velocities of the floatable items that enter the chamber.

As indicated in Section 4.2.4, a general analytical approach has been proposed in the literature to evaluate the floatables-removal efficiency of a baffle design. The next section provides details and examples of how these existing approaches can be applied.

\subsubsection{Application of Previous Approaches to Analyze Floatables- Removal Efficiency of Baffles}

\section{Non-Turbulent Assumption}

In the existing approaches, the floatables-removal efficiency of a baffle installation is determined based on a simplified analysis of item rise trajectories in the chamber. This simplified approach assumes that turbulence has no effect on floatables capture; subsequent steps of the analysis attempt to account for turbulent effects. A baffle placed into the chamber is assumed to capture floatables whose rise trajectories intercept it. From any given release point, the minimum rise velocity that intercepts the baffle $\left(V_{z, \text { min }}\right)$ is described by:

$$
V_{z, \min }=Z_{0} \cdot V_{x} / X_{0}
$$

where:

$Z_{0}=$ total vertical distance the floatable item must rise to reach the bottom of the baffle $(\mathrm{m})$,

$X_{0}=$ total horizontal distance over which a floatable item must travel to reach the baffle (m), and

$V_{x}=$ average horizontal velocity of the flow between the point of release and the baffle, for the peak flow rate at the design condition $(\mathrm{m} / \mathrm{s})$. 
Dalkir suggested that $X_{0}$ be assigned as the distance between the inlet to the chamber and the face of the baffle. $Z_{0}$ will be longest when the release point is at the invert of the inlet, and will be shortest when the release point is the crown of the inlet (or the maximum water surface, whichever is lower). Dalkir also suggested that the peak flow rate at the design condition be used to evaluate the baffle performance since the peak velocity will correspond to the minimum removal efficiency.

For a given baffle installation, the required rise velocity will vary depending upon the release point and the hydraulic condition. Items with rise velocities equal to or greater than $V_{z, \min }$ will intercept the baffle and are therefore captured. Items with rise velocities less than $V_{z, \text { min }}$ will not intercept the baffle and are assumed to discharge via the CSO.

Once the minimum rise velocity has been determined for a particular $Z_{0}$ (e.g. release elevation), the percentage of floatables intercepting the baffle can be assessed by checking the fraction of the floatables population that meets or exceeds this minimum rise velocity. This percentage value is readily available from a floatables rise-velocity probability distribution table or chart, such as shown on Figure 4.2. Unfortunately, at this time there is only one such distribution available, for floatables sampled from two CSOs in the Montreal area. In reality, the actual composition of floatables (and hence the rise-velocity distribution) will vary by location and over time. It is not known at this time whether this variability is significant. However, ongoing work in New York City promises to provide additional rise-velocity distributions to complement the existing data.

\section{Accounting for Turbulence}

Flow in sewers and in regulator chambers is turbulent. Unfortunately, the nature of turbulence, particularly turbulence within regulator chambers, is very complex and difficult to analyze. Turbulence can degrade baffle performance in a number of ways. First, turbulence can cause previously trapped floatable items to become re-entrained and to carry under the baffle. Without turbulence, a floatable item that rises to the surface is trapped by the baffle and is effectively removed from any flowing streamline. With turbulence, however, an item intercepted by the baffle may be subsequently re-entrained into another streamline and carried under the baffle to the overflow. Re-entrainment is more likely if the item is less buoyant, the flow is more turbulent, or if velocities under the baffle are higher.

To account for carry-under loss of floatables, Dalkir suggested that the bottom $15 \mathrm{~cm}$ of the baffle be ignored, based on laboratory observations that this portion of the baffle does not retain floatables. Therefore, for a floatable item to be captured, its trajectory must intercept the baffle at a point which is 
at least $15 \mathrm{~cm}$ from the bottom edge. Equation 4.1 can be modified to account for this carry-under zone:

$$
V_{z, \min }=\left(Z_{0}+Z_{d}\right) \cdot V_{x} / X_{0}
$$

where:

$$
\begin{aligned}
Z_{d}= & \text { depth of the carry-under zone (m); Dalkir et al. (1996) } \\
& \text { suggested } 0.15 \mathrm{~m} .
\end{aligned}
$$

The second way that turbulence degrades baffle performance is to effectively reduce the rise velocities of floatable items. In the non-turbulent case, floatable items rise at a steady rate. However, in real situations, turbulent mixing superimposes an almost random vertical pattern to the item's trajectory, with the net result typically inhibiting the item's ability to rise (Figure 4.4).

To account for the reduction in the effective rise velocity, Dalkir proposed that the root-mean-square velocity component of the vertical turbulent fluctuations must also be overcome when calculating the minimum required rise velocity:

$$
V_{z, \min }=\left(Z_{0}+Z_{d}\right) \cdot V_{x} / X_{0}+C \cdot V^{*}
$$

where:

$$
C=\text { experimentally determined coefficient for whichDalkir }
$$
et al. (1996) suggested a value of 1.0, and for which Cigana et al. (1998b) show a range of 0.4 to 1.6 , with a suggested value of 1.2 (see discussion below); and

$V^{*}=$ root-mean-square velocity component of the vertical turbulent fluctuations $(\mathrm{m} / \mathrm{s})$ :

$$
V^{*}=V_{x} \cdot n \cdot\left(g / R_{H}{ }^{1 / 3}\right)^{1 / 2}
$$

and:

$$
\begin{aligned}
& n= \text { Manning's roughness coefficient (typically about } \\
& 0.017 \text { for existing sewer applications), } \\
& g= \text { gravitational acceleration }\left(9.81 \mathrm{~m} / \mathrm{s}^{2}\right) \text {, and } \\
& R_{H}= \text { hydraulic radius (m), a function of water level: } \\
& \qquad R_{H}=A_{\text {flow }} / P_{\text {wet }}
\end{aligned}
$$

where:

$$
\begin{aligned}
A_{\text {flow }} & =\text { area of flow }\left(\mathrm{m}^{2}\right), \text { and } \\
P_{\text {wet }} & =\text { wetted perimeter }(\mathrm{m}) .
\end{aligned}
$$


It should be noted that the coefficient $C$ shown in Equation 4.3 was described by Simmons and Senturk (1977) for suspended particles as the product of the Van Karman constant (0.4) and the critical Rouse number, which, according to Cigana et al. (1998b), was reported by Van Rijn (1984) to range from 1 to 4 for suspended particles; hence the range of 0.4 to 1.6 reported by Cigana et al. (1998b). As discussed below, Cigana et al. (1998b) suggested that a value of 1.2 be used based on experimental data (see discussion below).

It should also be noted that Equation 4.4 is not intended to represent the turbulence imparted in regulator chambers by irregular flow sections and the resulting flow separation, vortices etc., which, although possibly significant, is beyond the scope of a simple analysis.

Cigana adopted a somewhat different approach to account for turbulent effects on baffle performance. Utilizing a rectangular channel, Cigana conducted rise-velocity tests, both in still water and in turbulent flow, of items typical in CSO discharges. Analysis of the results produced the following correlation between the rise velocity of a floatable in turbulent water and the rise-velocity in still water (Cigana et al., 1998c):

$$
K_{2}=1.2-0.6 \cdot V^{*}
$$

where:

$$
\begin{aligned}
K_{2}= & \text { ratio of the rise velocity in turbulent flow to the rise } \\
& \text { velocity in still water. }
\end{aligned}
$$

Note that $K_{2}$ can be greater than one for smaller values of $V^{*}$, meaning that under those less turbulent flow conditions, items can rise more quickly than under still-water conditions. In most cases, however, turbulence inhibits rising, and the minimum required rise velocity will be higher than calculated for the non-turbulent case, as follows:

$$
V_{z, \min }=K_{2} \cdot\left(\left(Z_{0}+Z_{d}\right) \cdot V_{x} / X_{0}\right)
$$

Cigana also applied the results of the rise-velocity tests to refine the coefficient $C$ used in Dalkir's approach. Cigana's findings were that a value of 1.2 should be used for $C$ instead of 1.0 (based on an $80 \%$ "experimental surfacing efficiency") or , according to a personal communication from John Cigana to the author on May 14, 1999, a value of 1.3 (based on a $50 \%$ "experimental surfacing efficiency").

It should be noted that, like Equation 4.3, Equation 4.7 is not intended to represent the complex turbulent factors imparted in regulator chambers by irregular flow sections and the resulting flow separation, vortices etc. Those factors are complex and beyond the scope of a simple approach. 


\subsubsection{Example Application of Existing Methods}

To illustrate the application of the existing approaches, consider the case of a regulator chamber in which the horizontal distance between the $1.22 \mathrm{~m}$ diameter inlet and the baffle is $2.74 \mathrm{~m}$, the width of the chamber is $2.44 \mathrm{~m}$, and the water level in the chamber is just above the crown of the inlet pipe, $1.52 \mathrm{~m}$ above the invert of the regulator. The bottom of the baffle leaves $0.84 \mathrm{~m}$ clearance under the bottom of the baffle. In this example, the inflow rate is $0.85 \mathrm{~m}^{3} / \mathrm{s}$, the overflow is $0.77 \mathrm{~m}^{3} / \mathrm{s}$, and the remaining $0.08 \mathrm{~m}^{3} / \mathrm{s}$ is conveyed to the interceptor. Mannings $n$ is 0.013 in this particular case.

\section{Step 1: Non-Turbulent Assumption}

To begin, we start by ignoring the effects of turbulence, so that Equation 4.1 applies. Conservatively taking the maximum horizontal flow velocity (here, the flow velocity in the inlet conduit), then $V_{x}=Q / A=0.85 /\left(\pi 1.22^{2} / 4\right)=0.73 \mathrm{~m} / \mathrm{s}$. With a horizontal distance of $2.74 \mathrm{~m}$ between the inlet and the baffle, $X_{0}=2.74$ $\mathrm{m}$. For a floatable item released from the invert of the inlet, $Z_{0}$, the vertical rise required, is $0.53 \mathrm{~m}$. The minimum required rise velocity for capture is then given by Equation 4.1: $V_{z, \min }=Z_{0} . V_{x} / X_{0}=(0.53)(0.73) /(2.74)=0.14 \mathrm{~m} / \mathrm{s}$, or $14 \mathrm{~cm} / \mathrm{s}$, which, according to Figure 4.2 , corresponds to a floatablesremoval efficiency of $12 \%$ (since only $12 \%$ of CSO floatables have rise velocities of at least $14 \mathrm{~cm} / \mathrm{s}$ ). This is the worst-case removal since $Z_{0}$ is greatest when taken from the invert of the inlet. Floatables-removal efficiency increases for higher release points until the release point matches the elevation of the bottom of the baffle, which occurs $0.53 \mathrm{~m}$ above the invert of the inletjust below the midpoint of the inlet. From that point and higher, the calculated floatables-removal efficiency is essentially $100 \%$.

\section{Step 2: Accounting For Turbulence}

As described in Section 4.3.2, the two existing analytical methods (Equations 4.3 and 4.7) both utilize $R_{H}$ (the hydraulic radius) and $V^{*}$ (the velocity component of the vertical turbulent fluctuations) to account for the turbulence associated with boundary friction. Calculating these parameters using Equations 4.4 and 4.5 so that $R_{H}$ is minimized (thereby using in-chamber characteristics to maximize the calculated turbulent effects, thereby producing a conservative capture efficiency):

$R_{H}=A_{\text {flow }} / P_{\text {wet }}=$ taken at the vertical plane of the baffle, (Flow Depth Under Baffle $) *($ Chamber Width $) /(2 *$ Flow Depth Under Baffle $+2 *$ Chamber Width $)=(0.84)(2.44) /(2 * 0.84+2 * 2.44)=0.31 \mathrm{~m}$, and $V^{*}=V_{x} \cdot n \cdot\left(g / R_{H}^{1 / 3}\right)^{1 / 2}$ $=(0.73)(0.013)\left(9.81 / 0.31^{1 / 3}\right)^{1 / 2}=0.036 \mathrm{~m} / \mathrm{s}$. 
The first approach to account for turbulence uses Equation 4.3 to determine the required rise velocity:

$$
\begin{aligned}
& V_{z, \min }=\left(Z_{0}+Z_{d}\right) \cdot V_{x} / X_{0}+C \cdot V^{*} \\
& =(0.53+0.15)(0.73) /(2.74)+(1)(0.036)=0.22 \mathrm{~m} / \mathrm{s},
\end{aligned}
$$

where $Z_{0}$ is again taken as the worst-case release point, and Dalkir's suggested drawdown zone of $0.15 \mathrm{~m}$ and $C$ coefficient of 1.0 are used. Using Cigana's suggested value of 1.2 for $C$ does not significantly increase the result. The second approach for the turbulent case utilizes Equation 4.7 to determine the required rise velocity, for which Equation 4.6 must first be solved:

$$
\begin{aligned}
& K_{2}=1.2-0.6 \cdot \mathrm{V}^{*}=1.2-(0.6)(0.036)=1.18 \\
& V_{z, \min }=K_{2} \cdot\left(\left(Z_{0}+Z_{d}\right) \cdot V_{x} / X_{0}\right)=(1.18)((0.53+0.15)(0.73 / 2.74)= \\
& 0.21 \mathrm{~m} / \mathrm{s}=21 \mathrm{~cm} / \mathrm{s} .
\end{aligned}
$$

In this example, both turbulent approaches yield similar results for the minimum required rise velocity. Based on Figure 4.2, this corresponds to a floatables-removal efficiency of about $5 \%$. Again, this is the worst-case because the release point maximizes the required rise for capture. Floatablesremoval efficiency will increase for higher release points until a level of $0.15 \mathrm{~m}$ higher than the bottom edge of the baffle. From that point and higher, the calculated floatables-removal efficiency will be $90 \%$ using Equation 4.3, or essentially $100 \%$ using Equation 4.7.

Again, it should be emphasized that neither method accounts for the turbulence associated with the irregular flow sections of regulator chambers and the resulting flow separation, vortices etc. Indeed, whether any simple analytical approach can successfully estimate floatables-removal efficiency without accounting for those factors must be determined through model tests, as discussed further below.

\subsection{Proposed Approach to Analyze Floatables- Removal Efficiency}

This section discusses some of the shortcomings associated with the existing approaches for analyzing floatables-removal efficiency and presents three solutions to address these shortcomings. First, a spreadsheet model was set up to more easily determine the relevant dimensions and parameters and to facilitate multiple calculations and integrations. Second, a new approach was developed to account for vertical variations in flow path between the inlet and the baffle. Third, a refinement was made to account for floatables captured in the underflow. The following sections describe each of these improvements. Taken together, these improvements comprise the new, proposed modeling 
approach. Each of the improvements is compatible with the previous approaches, with which they can be coupled. Section 4.5 presents a comparison of results calculated using the proposed model and the predecessor approaches for several cases where there are existing data.

\subsubsection{Development of a Spreadsheet Model}

One practical disadvantage of using the existing approaches is that they require tedious calculations. Because the expressions for minimum rise velocity (Equations 4.1,4.2, 4.3, and 4.7) are valid for a single release point, obtaining overall performance results can require many calculations. In addition, changes in the input conditions, such as a different water-surface elevation, can require re-assessment of the geometry and can change pertinent dimensions required for input. Furthermore, relating the minimum rise velocity to floatablesremoval efficiency requires manual inspection of a floatables distribution curve, such as shown on Figure 4.2. For the same reasons, performing sensitivity analyses or changing other input conditions is equally tedious.

To address these problems, the first refinement to the existing analytical approaches was the development of a spreadsheet model. A spreadsheet format was selected because it allows the user to immediately gage the sensitivity of the results to changes in one or more input conditions. In addition, it facilitates multiple calculations, allowing the user to obtain overall performance results (instead of results for just a single release point) and to easily compare results of different analytical approaches for the same input conditions. Another advantage is that it allows the inputs to be standardized; therefore, input can be entered once and used for any analytical approach, and changing conditions does not require re-assessing which dimensions are pertinent to the calculation. Finally, the spreadsheet format employs a best-fit polynomial correlation to compute the percentage of CSO floatables removed given a particular risevelocity (using a rise-velocity distribution such as shown on Figure 4.2).

\section{Standardizing Model Input}

The spreadsheet model has one section for input and one section for output. The input section is organized into several blocks based on the input type. For example, one block contains structural and water-surface elevations; another contains distances and clearances; another contains cross-sectional shapes and areas; another contains flows; and another contains flow velocities. The user enters some parameters, and the spreadsheet calculates others. Entered parameters are distinguished from calculated parameters by labels and color coding, but the user has the option to override any internally calculated value simply by entering the desired value into the cell. 
To facilitate data entry, the spreadsheet model is set up to accept all entered values in U.S. units. In the author's experience, baffle installations are typically retrofits in existing regulator chambers. The dimensions of these chambers are typically available in U.S. units from as-built drawings that indicate key elevations with respect to some datum, along with some measurements such as pipe diameters and weir heights. Entered parameters are internally converted to metric equivalents for the computations, and both the U.S. and metric values are shown in the spreadsheet.

\section{Sensitivity Analyses and Simultaneous Computation of Multiple Approaches}

The spreadsheet also allows the user to vary other assumed inputs to perform sensitivity analyses. For example, to account for carry-under loss of floatables, the user can select the size of the baffle's drawdown zone (the portion of the baffle that does not effectively retain floatables; Dalkir suggested a value of 15 $\mathrm{cm}$ ). The user can also manipulate the weighting factors used to determine the average flow velocity in the chamber from the velocities calculated at different locations in the chamber.

The spreadsheet has multiple blocks for model output. Each block designates the results of a particular modeling approach. Results for selected release points corresponding to the worst, best and typical cases are shown in the top portion of each block. Although these cases provide the range of floatables-removal efficiency for the baffle installation, they do not necessarily indicate the overall performance of the installation, particularly when the range is large.

\section{Estimating Overall Floatables-Removal Efficiency}

To estimate the overall floatables-removal efficiency of the baffle installation, a method was developed to essentially integrate the calculated performance over the entire depth of flow. The spreadsheet model accomplishes this by dividing the inlet conduit into 20 slices, calculating the floatables-removal efficiency of each slice, and then calculating the overall efficiency by weighting the results for each slice based upon its percentage contribution of flow. The contribution of flow from each slice is estimated using the shape of the conduit.

Integration calculations are shown in the output block. For each of the 20 horizontal slices, a row in the output block shows slice characteristics, such as relative contribution to the flow, floatables-removal efficiency, and relative contribution to floatables capture. Results of the integration are highlighted at the bottom of the output block and in a summary output block at the top of the spreadsheet. 


\subsubsection{Accounting for Flow Path (Streamlines)}

The previous approaches assume that the baffle will intercept all floatables that are released from elevations higher than the bottom edge of the baffle (notwithstanding adjustments for turbulence). This assumption relies on the rise trajectories not being impacted by the flow path in the regulator chamber. In reality, the floatables are directed along flow paths which are significantly affected by the presence of the baffle, changes in invert, and other factors. As shown on Figure 4.5 (section), most of the flow is directed along a path under the baffle from the inlet toward the outlets. To intercept the baffle, an item must overcome not only the vertical distance from its release point to the baffle, but also any downward velocity component imparted from the flow path. This section describes the new approach developed to account for a more realistic flow path through the regulator and its impacts on floatables-removal efficiency.

The revised flow path used in the new approach is enveloped by two streamlines: a bottom streamline extending from the invert of the inlet to the invert of the regulator directly under the baffle, and a top streamline extending from the crown of the inlet (or maximum water surface elevation in the inlet) to the bottom edge of the baffle. In this new approach, a floatable item traveling
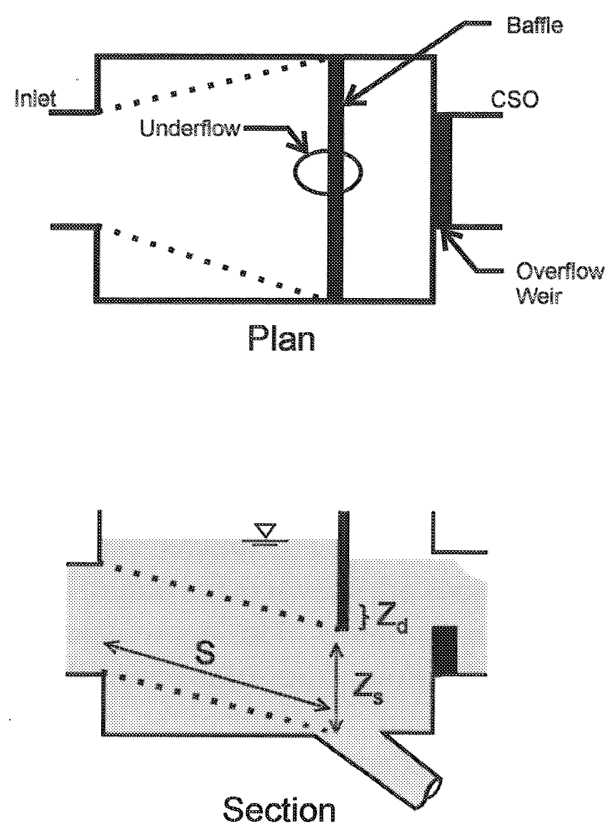

Figure 4.5 Simplified flow path. 
in the top streamline must rise some (albeit infinitesimal) distance out of the streamline to intercept the baffle, regardless of the release point. Similarly, an item in the bottom streamline must rise a distance equal to the clearance between the invert of the regulator and the bottom of the baffle to intercept the baffle. For intermediate streamlines, floatables must rise some distance that is proportioned between the top and bottom cases. This approach, explained further below, is a simplification of the real streamlines, but nevertheless represents an improvement over the previous approach.

Assuming that all streamlines flow at similar velocities, then for a floatable item initially in a particular streamline, the minimum rise velocity required to intercept the baffle may be estimated by:

$$
V_{z, \text { min }}=\left(Z_{s}+Z_{d}\right) / t_{a}
$$

where:

$$
\begin{aligned}
& V_{z, \text { min }}=\text { minimum rise velocity required to intercept the baffle } \\
& (\mathrm{m} / \mathrm{s}) \text {, } \\
& Z_{s}=\text { vertical distance in the plane of the baffle from the } \\
& \text { streamline to the bottom of the baffle (m), } \\
& Z_{d}=\text { depth of the carry-under or drawdown zone, as } \\
& \text { described previously (m), and } \\
& t_{a}=\text { time available }(\mathrm{s}) \text { : } \\
& t_{a}=S / V_{s}
\end{aligned}
$$

where:

$$
\begin{aligned}
S= & \text { length along the streamline measured from inlet sec- } \\
& \text { tion to the baffle section }(\mathrm{m}), \text { and } \\
V_{s}= & \text { average velocity along the streamline }(\mathrm{m} / \mathrm{s})
\end{aligned}
$$

Note that, for computational simplicity, straight-line distances were calculated for both the top and the bottom streamlines, as follows:

$$
S=\left(\Delta Z^{2}+\Delta X^{2}\right)^{1 / 2}
$$

where:

$$
\begin{aligned}
\Delta Z= & \text { change in elevation of the streamline between the } \\
& \text { vertical planes of the inlet and the baffle }(\mathrm{m}), \text { and } \\
\Delta X= & \text { horizontal distance between the vertical planes of the } \\
& \text { inlet and the baffle }(\mathrm{m}) .
\end{aligned}
$$

For example, if the distance along the streamline is $10 \mathrm{~m}$ between the inlet and the plane of the baffle, and the velocity along the streamline is $5 \mathrm{~m} / \mathrm{s}$, then it will take 2 seconds for an item to travel that distance. If the vertical distance between the streamline and the baffle is $1 \mathrm{~m}$ in the plane of the baffle, then the minimum floatables rise velocity required to intercept the baffle is $1 \mathrm{~m}$ per $2 \mathrm{~s}$, 
or $0.5 \mathrm{~m} / \mathrm{s}$. The floatables-removal efficiency can then be calculated for this streamline, using a rise-velocity distribution curve (such as Figure 4.2) as described in the previous approaches. The overall baffle efficiency can also be calculated as before by integrating over the depth of flow at the inlet.

Because most regulator chambers open up into a wider cross section than the inlet conduits, the flow emerging from the inlet typically fans out laterally (Figure 4.5, plan). Depending upon the degree to which the widening occurs, the streamlines along the outside walls can be somewhat longer than the central streamlines. As a result, the outer streamlines will have longer travel times and hence higher removal efficiencies than the central streamlines. However, in the interest of simplicity and to maintain a degree of conservatism in the calculation, only the central streamlines are considered and lateral variations are ignored.

By accounting for the downward velocity component of the flow path, this approach produces lower floatables-removal efficiencies than the previous approaches, all else equal. Indeed, this approach is compatible with and can be easily coupled with any of the previous approaches simply by replacing $Z_{0}$ or $\left(Z_{0}+Z_{d}\right)$ with $Z_{s}, V_{x}$ with $V_{s}$, and $X_{0}$ with $S$ in Equations 4.1 through 4.7, as appropriate. For example, Equations 4.1, 4.3 and 4.7 would be expressed as:

$$
\begin{aligned}
& V_{z, \min }=\left(Z_{s}+Z_{d}\right) \cdot V_{s} / S \\
& V_{z, \min }=\left(Z_{s}+Z_{d}\right) \cdot V_{s} / S+C \cdot V^{*} \\
& V_{z, \min }=K_{2} \cdot\left(\left(Z_{s}+Z_{d}\right) \cdot V_{s} / S\right)
\end{aligned}
$$

This will be demonstrated in Section 4.4 .4 below.

\subsubsection{Capture in the Underflow Connection to the Interceptor}

The previous approaches assumed that floatables retained by the baffle would be captured at the end of the storm, when water levels subside and the floatables would be diverted to the underflow connection to the interceptor. Direct capture of floatables by the underflow connection during the storm was not addressed. However, depending upon the proportion of flow diverted to the underflow versus overflowing the weir, the direct capture of floatables in the underflow can be significant. Furthermore, a true assessment of the floatablesremoval efficiency of a baffle installation must relate the net change in capture from the pre-baffle condition to the post-baffle condition. This section 
describes the new approach developed to estimate the capture of floatables by the underflow.

Whenever the regulator diverts a portion of the inlet flow to the underflow, a portion of the influent floatables may also be diverted to the underflow (see Figure 4.6), even if the underflow draws from the bottom of the regulator chamber. All else equal, more floatables are likely to be captured in the underflow if the proportion of flow diverted to the underflow is higher, and floatables with lower rise velocities are more likely to be diverted to an underflow drawing flow from the bottom of the regulator. However, it should be noted that the specific hydraulics of each situation could conceivably result in a greater underflow to adversely affect floatables capture by causing increased carry under. These effects are beyond the scope of this simplified analysis.

The approach to estimate floatables capture in the underflow follows a similar reasoning as the approach to determine floatables capture by the baffle, except that floatables rising out of streamlines captured in the underflow escape capture in the underflow. The first step in the new approach is to determine

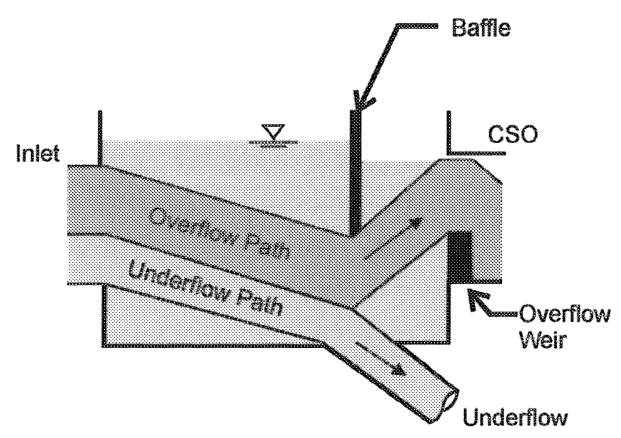

Figure 4.6 Underflow capture.

which streamlines flow to the underflow and which flow to the overflow. A rough estimate is obtained by calculating the fraction of the inflow that is diverted to the underflow and applying this fraction to the height of the total flow path at the location of the underflow. For example, if the inflow to the regulator is $1.0 \mathrm{~m}^{3} / \mathrm{s}$, of which $0.2 \mathrm{~m}^{3} / \mathrm{s}$ is diverted to the interceptor, then the bottom $20 \%$ of the flow path is assumed to divert to the underflow. The upper $80 \%$ of the flow path is assumed to exit via the CSO. Now consider a floatable item in the bottom streamline. This item will be captured in the underflow unless it rises out of the lower $20 \%$ of the flow path. Floatable items in the bottom $20 \%$ of the flow path have the possibility of being captured in the underflow, but the likelihood diminishes for streamlines approaching the $20 \%$ level. 
The rise velocity required for a floatable item to escape capture in the underflow may be described for any release point corresponding to a streamline leading to the underflow:

$$
V_{z \cdot \min }=Z_{u} \cdot V_{s} / S+C \cdot V^{*}
$$

where:

$$
\begin{aligned}
& V_{z, \min }=\text { minimum rise velocity required to escape the under- } \\
& \text { flow zone from the release point }(\mathrm{m} / \mathrm{s}) \text {; } \\
& Z_{u}=\text { vertical distance from streamline corresponding to } \\
& \text { the release point to the top of the underflow zone, as } \\
& \text { measured in the vertical plane of the baffle }(\mathrm{m}) \text {; } \\
& V_{s}=\text { average velocity (between the inlet and the vertical } \\
& \text { plane of the baffle) along the streamline correspond- } \\
& \text { ing to the release point }(\mathrm{m} / \mathrm{s}) \text {; } \\
& S=\text { length of the streamline (between the inlet and the } \\
& \text { vertical plane of the baffle) along the streamline } \\
& \text { corresponding to the release point }(\mathrm{m}) \text {; } \\
& C=\text { experimental factor described above; and } \\
& V^{*}=\text { RMS velocity component of the vertical turbulence } \\
& \text { fluctuations, from Equation } 4.4(\mathrm{~m} / \mathrm{s}) \text {. }
\end{aligned}
$$

As indicated above, only items released into streamlines leading to the underflow have the possibility of conveying floatables to the underflow. To identify these underflow streamlines, the model employs a simplistic method based on the underflow fraction of the inflow and the depth of the flow. These streamlines begin in the vertical plane at the entrance of the inflow conduit to the regulator, where they occur over a range of depths as described by:

$$
d_{i}=\left.\right|_{0} ^{\left(Q_{u} / Q_{i}\right) \cdot D_{i}}
$$

where:

$$
\begin{aligned}
d_{i}= & \text { depth of an underflow streamline }(\mathrm{m}) \text { at the inlet } \\
& \text { entrance to the regulator; } \\
Q_{u}= & \text { underflow rate }\left(\mathrm{m}^{3} / \mathrm{s}\right) ; \\
Q_{i}= & \text { inflow rate }\left(\mathrm{m}^{3} / \mathrm{s}\right) ; \text { and } \\
D_{i}= & \text { maximum depth of flow }(\mathrm{m}), \text { as measured from the } \\
& \text { inlet invert to water-surface elevation in the inlet, at } \\
& \text { the entrance to the regulator. }
\end{aligned}
$$

The streamlines continue through the regulator to the vertical plane of the regulator, where their depths are described by: 


$$
d_{b}=\mid \begin{aligned}
& \left(Q_{u} / Q_{i}\right) \cdot D_{b} \\
& 0
\end{aligned}
$$

where:

$$
\begin{aligned}
d_{b}= & \text { depth of an underflow streamline }(\mathrm{m}) \text { in the vertical } \\
& \text { plane of the baffle; } \\
D_{b}= & \text { maximum depth of flow }(\mathrm{m}) \text { under the baffle in the } \\
& \text { vertical plane of the baffle. }
\end{aligned}
$$

Overlying streamlines and the floatables they convey do not have the opportunity to be captured in the underflow and hence are not part of the analysis of underflow capture. Only streamlines between depth zero (along the invert) and a depth equal to the proportion of the underflow (relative to the inflow) will be subject to the analysis of underflow capture.

The percentage of floatables that rise out of the underflow zone from a particular underflow streamline relates to $V_{z \text { min }}$ according to a rise-velocity distribution of the CSO-floatables population (such as shown on Figure 4.2). The remaining floatables initially entering the chamber in that particular streamline are captured by the streamline.

In the case of underflow capture, floatables with lower rise velocities are more likely to be captured than floatables with higher rise velocities (whereas the reverse is true for capture with a baffle). Therefore, the fraction of floatables exceeding the critical rise velocity will escape capture, and it is the remaining fraction that will be captured by the underflow.

This method of estimating the floatables-removal efficiency associated with the underflow is compatible with and can be easily coupled with any of the previous approaches. Note that this method will work to estimate the floatablesremoval efficiency associated with the underflow regardless of whether there is a baffle. If there is no baffle, then the overall floatables-removal efficiency will equal the efficiency of the underflow. If there is a baffle, the total removal efficiency will be the sum of the efficiencies of the baffle and of the underflow. The net improvement in floatables-removal efficiency afforded by the baffle (the difference between the post-baffle and pre-baffle efficiencies) is an important parameter in the evaluation of the cost effectiveness of the installation.

\subsection{Example Application}

To illustrate the improved analytical approaches described in sections 4.4 .2 and 4.4.3, the example in 4.4.3 is repeated below using the revised approach. 


\section{Accounting for Flow Path}

In the example application described in Section 4.3.3, $\Delta Z$, the change in elevation between the invert of the inlet conduit and the invert of the regulator chamber under the baffle, is $0.30 \mathrm{~m}$. $(X$, the horizontal distance between the inlet and the baffle, is $2.74 \mathrm{~m}$. Using Equation $4.10, \mathrm{~S}=\left(0.3^{2}+2.74^{2}\right)^{1 / 2}=2.76$ $\mathrm{m}$. Making the conservative assumption that the flow velocity does not slow in the chamber, $V_{s}=0.73 \mathrm{~m} / \mathrm{s}$. According to Equation $4.9, t_{a}=S / V_{s}=(2.76) /$ $(0.73)=3.78 \mathrm{~s}$. $Z_{s}$, the required vertical rise from the bottom streamline to the bottom of the baffle, is $0.84 \mathrm{~m}$, the clearance under the baffle. Assuming that there is a zero drawdown zone for the non-turbulent case, $Z_{d}$ is $0.0 \mathrm{~m}$ and Equation 4.8 or Equation 4.11 then yields: $V_{z, \min }=\left(Z_{s}+Z_{d}\right) / t a=\left(Z_{s}+Z_{d}\right) . V_{s}$ $/ S=(0.84+0.0) /(3.78)=0.22 \mathrm{~m} / \mathrm{s}=22 \mathrm{~cm} / \mathrm{s}$. From Figure 4.2 , this rise velocity represents a floatables-removal efficiency of about $5 \%$. The efficiency increases for higher release points, with the maximum efficiency for release points at the inlet crown. For the associated streamline, $Z_{s}$ is zero and $\Delta Z$ is 0.69 $\mathrm{m}$. Using Equations 4.10 and $4.9, \mathrm{~S}=\left(0.69^{2}+2.74^{2}\right)^{1 / 2}=2.82 \mathrm{~m}$, and $t_{a}=S / V_{s}$ $=(2.84) /(0.73)=3.89 \mathrm{~s}$. Equation 4.8 then gives: $V z, \min =(Z s+Z d) / t a=$ $(0.0+.15) /(3.89)=0.038 \mathrm{~m} / \mathrm{s}=3.8 \mathrm{~cm} / \mathrm{s}$, which corresponds to a floatablesremoval efficiency of about $89 \%$.

Assuming that there is turbulence, then Equations 4.12 or 4.13 can be used. Taking Dalkir's suggested values of $0.15 \mathrm{~m}$ for $Z d$ and 1.0 for $C$, Equation 4.12 gives: $V z$, $\min =(Z s+Z d) . V s / S+C . V^{*}=(0.84+0.15)(0.73) /(2.76)+$ $(1.0)(0.036)=0.30 \mathrm{~m} / \mathrm{s}=30 \mathrm{~cm} / \mathrm{s}$, which corresponds to a floatables-removal efficiency of about $3 \%$. Similarly, Equation 4.13 gives: $V_{z, \text { min }}=K_{2} \cdot\left(Z_{s}+Z_{d}\right)$ . $\left.V_{s} / S\right)=(1.18)(0.84+.15)(0.73) /(2.76)=0.31 \mathrm{~m} / \mathrm{s}=31 \mathrm{~cm} / \mathrm{s}$, which also corresponds to a floatables-removal efficiency of about $3 \%$. For the top streamline, the removal efficiency would be $V_{z, \min }=\left(Z_{s}+Z_{d}\right) . V_{s} / S+C . V^{*}$ $=(0.0+0.15)(0.73) /(2.84)+(1.0)(0.036)=0.074 \mathrm{~m} / \mathrm{s}=7.4 \mathrm{~cm} / \mathrm{s}$, or a removal efficiency of about $38 \%$.

\section{Accounting for Underflow Capture}

In this example, the underflow to inflow ratio is $\left(0.85 \mathrm{~m}^{3} / \mathrm{s}\right) /\left(0.08 \mathrm{~m}^{3} / \mathrm{s}\right)$, or 0.09 . Therefore, the bottom $9 \%$ of the streamlines are assumed to flow to the underflow. This corresponds to the bottom $9 \%$ of the clearance under the baffle, or up to a height of $0.08 \mathrm{~m}$ above the invert. For the bottom streamline, $\mathrm{Zu}$ is the full $0.08 \mathrm{~m}$, so according to Equation 4.14, $\mathrm{Vz}$, $\min =Z_{u} . V_{s} / S+C$ . $V^{*}=(0.08)(0.73) /(2.84)+(1.0)(0.036)=0.06 \mathrm{~m} / \mathrm{s}=6 \mathrm{~cm} / \mathrm{s}$. According to Figure 4.2 , about $72 \%$ of CSO rise velocities exceed $6 \mathrm{~cm} / \mathrm{s}$, so about $28 \%$ have rise velocities that are insufficient to rise out of the bottom streamline before being captured in the underflow. Therefore, the overall floatables-removal 
efficiency for the bottom streamline is (assuming turbulence) about 31\%$28 \%$ captured in the underflow and $3 \%$ captured by the baffle. The underflow capture efficiency decreases for higher streamlines and reaches zero for streamlines higher than $0.08 \mathrm{~m}$ above the regulator invert in the plane of the baffle.

\section{Integrating Over the Inlet Depth and Comparison to Experimental Data}

To determine the overall floatables-removal efficiency, the proposed spreadsheet model was used to integrate over the depth of flow and to estimate the average flow velocity within the regulator. The model used the same inputs and numerical techniques for integration for each of three analytical approaches: Dalkir's approach (Equation 4.3), Cigana's approach (Equation 4.7), and the approach presented herein (Equations 4.12 and 4.14). The resulting overall floatables-removal efficiencies are presented in Figure 4.7 ("high-flow condition, with baffle"). This example condition was adopted from an experimental test conducted by Alden Laboratories, so monitoring data is available for comparison to the model calculations. Figure 4.7 also shows model results for a low-flow condition and for a no-baffle condition in the same regulator configuration. A summary of the test conditions follows below.

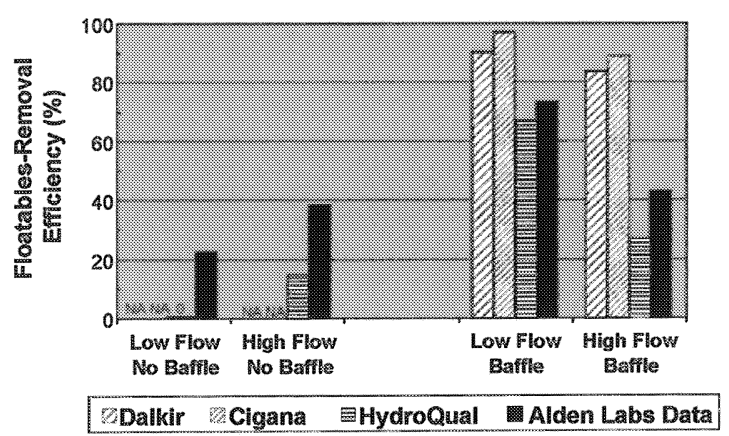

Figure 4.7 Comparison of model results and laboratory data: overall floatables removal efficiency.

A total of four test conditions were simulated with the proposed model: two flow conditions, each with and without a baffle. The low-flow tests were conducted with an inflow rate of $0.42 \mathrm{~m}^{3} / \mathrm{s}$, an underflow rate of $0.04 \mathrm{~m}^{3} / \mathrm{s}$, and an overflow rate of $0.39 \mathrm{~m}^{3} / \mathrm{s}$. The high-flow tests were conducted with twice the flow rates of the low-flow case. All tests were conducted for a steady-state condition. Because water levels in the high-flow tests exceeded the crown of 
the inlet and overflow conduits, some floatables were retained on the regulator wall, above the overflow conduit. The model accounts for this retainage by assuming that the regulator wall is a baffle whose bottom edge is at the crown of the overflow conduit.

As shown in Figure 4.7, the previous approaches of Dalkir and Cigana (as integrated with the spreadsheet model) estimate removal efficiencies that are consistently higher than the revised approach and the monitoring data. The revised approach presented herein better matches the experimental data. These results are compared in Figure 4.8, which compares the observed removal efficiency of the baffle alone (without capture in the underflow) to the calculated baffle efficiency. Using the revised approach, the calculated floatables-removal efficiency of the baffle closely matches the observed removal efficiency. Therefore, the discrepancy between the calculated and observed overall removal efficiencies in these cases appear to be due to inaccurate prediction of the underflow capture. One possible explanation for this discrepancy could be the difference between the rise-velocity characteristics of the floatables used in the Alden tests versus those for the Montreal floatables, described by the distribution shown on Figure 4.2. Indeed, the Alden test floatables were based upon a floatables matrix that has a high proportion of cigarette butts, items that lose buoyancy after a short period of time in water. A high proportion of low-buoyancy items would have tended to produce higherthan-predicted underflow captures in the tests.

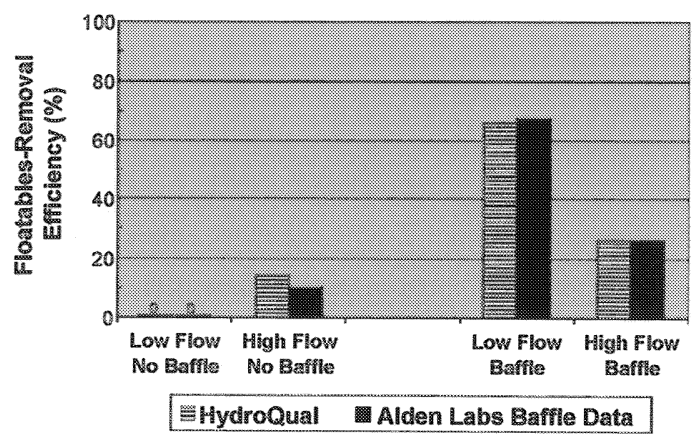

Figure 4.8 Comparison of model results and laboratory data: floatable removal efficiency of baffle only.

It should be noted that these four tests do not constitute a model validation. However, the results are favorable and bode well for the revised modeling approach. 


\subsection{Summary and Conclusions}

An improved analytical approach has been developed to assess the floatablesremoval efficiency of a baffle installation in a combined-sewer regulator chamber. The improvements include a more realistic treatment of flow through the regulator, a provision to estimate capture of floatables via the underflow as well as by the baffle, and an easy-to-use spreadsheet framework that allows calculation of the overall floatables-removal efficiency through an integration over the entire flow depth. Significantly, the improved approach is capable of calculating the floatables-removal efficiency via the underflow. This capability enables evaluation of the pre-baffle condition, which is necessary to assess the net improvement in floatables capture that the baffle could provide. Based upon application to a number of experimental conditions, the improved approach appears to compute floatables-removal efficiencies more accurately than previous approaches.

Further refinements to the analytical approach should improve the analysis. The phenomenon of floatation in turbulent flow is very complex. The simple analytical approach proposed herein does not account for the complex hydraulics in the regulator chamber (such as flow separation, vortices and eddies) and the corresponding impacts on floatables capture, nor does it account for any variation in the vertical distribution of floatable items at the inlet to the regulator. Furthermore, the proposed approach does not address lateral variation in the flow path and its effect on floatables capture. Future improvements will attempt to refine the estimation of the average flow speed within the regulator chamber, as well as the effect of simple lateral variation of flow path through the regulator.

Additional laboratory and field-monitoring data are also necessary to improve the understanding of baffle performance and to provide a means to assess the analytical approaches. The fact that analytical approaches base floatables-removal efficiency upon a singler assessment of the floatables risevelocity distribution of Montreal CSO floatables limits the confidence associated with their applicability to floatables for other locations. Work being performed in New York City to further characterize rise velocities for CSO floatables will make this aspect of the analysis more robust. Finally, insufficient field-monitoring data currently exists to validate any analytical approach to calculate baffle performance. Results of field-monitoring investigations now underway in Boston and New York City promise to provide this information. Examples of the application of the proposed approach to the test locations in New York City are available from the author. 


\section{References}

Allison, R.A., 1999. "Innovative Technology Reduces Stormwater Trash.” Public Works, February, 1999, pp. 28-32.

Cigana, John, Martin Couture, Martial Champigny, Benoit Gagne, and Charles Meunier, 1998a. "Proposal of a method for floatables interception in CSOs." Proceedings of the 1998 NOVATECH Conference: Innovative Technologies in Urban Storm Drainage, Lyon, France. May 4 - 6, 1998, pp. 437-441.

Cigana, John, Giscard Lefebvre, and Claude March, and Martin Couture, 1998b. "Design criteria of underflow baffles for control of floatables." Water Science and Technology, IAWQ, London, England, Vol. 38, No. 10, 1998, pp. 57-63.

Cigana, John, Martin Couture, Giscard Lefebvre, and Claude Marche, 1998c. "Evidence of a critical velocity in underflow baffles design for floatables control in combined sewer overflows." Proceedings of the 1998 Water Environment Federation (WEF) Conference: Advances in Urban Wet Weather Pollution Reduction, Cleveland, Ohio. June 28 - July 1, 1998, pp. 275-281.

Cigana, John, Martin Couture, Charles Meunier, and Yves Comeau, 1999. "Determination of the vertical velocity distribution of floatables in CSOs." Water Science and Technology, IAWQ, London, England. Vol. 39, No. 2, 1999, pp. 69-73.

Crane, Christopher M. and Phillip A. Davidson, 1998. "The Wethersfield Cove Floatables Control Management Plan." Presented at the New York Water Environment Association Conference, February 4, 1998.

Dalkir, Oscan, Hubert Demard, Benoit Gagne, and Martin Couture, 1996. "Combined sewer overflows: Hydraulic study of overflow basins equipped with weirs and underflow baffles for floatables removal." Prepared and published by CEGEO Technologies, Inc. and John Meunier, Inc., August, 1996.

Furrier, Gerald, 1998. "Technical memorandum: Underflow baffles for floatables control at BMC Regulators." Prepared by Camp Dresser \& McKee, Inc. for the Massachusetts Water Resources Authority, December 14, 1998.

Heath, Gregory R., Michael P. Collins, Brian W. Daly, and Donald E. Walker, 1996. "CSO floatables control for greater Boston, Massachusetts." Proceedings of the 1996 Water Environment Federation (WEF) Specialty Conference: Urban WetWeather Pollution Specialty Conference, Quebec City, Quebec. June 16-19, 1996, pp. 6-11-6-22.

HydroQual, Inc., 1992. "City-Wide Floatables Study, Subtask 11.1, Third Interim Report: Sources, Fate and Control of Floatable Materials, Preliminary Findings." Prepared for the City of New York Department of Environmental Protection, Bureau of Environmental Engineering, Division of Water-Quality Improvement.

HydroQual, Inc., 1993. "City-Wide Floatables Study, Final Report, Sources, Fate and Control of Floatable Materials in New York Harbor." Prepared for the City of New York Department of Environmental Protection, Bureau of Environmental Engineering, Division of Water-Quality Improvement. 
HydroQual, Inc., 1995. "City-Wide Floatables Study, Floatables Pilot Program Final Report, Evaluation of Non-Structural Methods to Control Combined and Storm Sewer Floatable Materials." Prepared for the City of New York Department of Environmental Protection, Bureau of Environmental Engineering, Division of Water-Quality Improvement.

Metcalf \& Eddy, 1996. "Draft technical memorandum on pre-design planning for floatables control at outfalls not associated with other CSO controls." Prepared for the Massachusetts Water Resources Authority, January, 1996.

Newman, Thomas L., William M. Leo, and Robert Gaffoglio, 2000. "Characterization of Urban-Source Floatables." Proceedings of the Water Environment Federation (WEF) Specialty Conference on Wet-Weather Pollution Control, Rochester, New York, May 7-10, 2000. (WEF Order No. CD0033)

Paradis, Jean-Francois, Hubert Demard, and Martial Champigny, 1996. "Floatables: How fine the screen: Field data." Proceedings of the 1996 Water Environment Federation (WEF) Specialty Conference: Urban Wet-Weather Pollution Specialty Conference, Quebec City, Quebec. June 16-19, 1996, pp. 3.51 - 3.58.

Simmons, D.B. and F. Senturk, (1977). Sediment Transport Technology. Water Resources Publications, Fort Collins, Colorado.

St. John, John P., William M. Leo, and Robert Gaffoglio, 1994. "City Streets and CSOs." Water Environment and Technology, June, 1994, pp. 39-43.

Turner, Richard R., 1995. "Floatables Control and the New USEPA CSO Policy." Proceedings of the Water Environment Specialty Conference, Toronto, Ontario, June 4-7, 1995, pp. 2.1-2.10.

USEPA, 1995. "Combined Sewer Overflows - Guidance For Nine Minimum Controls." EPA 832-B-95-003, May 1995.

Van Rijn, L.C., 1984. "Sediment Transport, Part II: Suspended Load Transport." Journal of Hydraulic Engineering, 110 (11), 1613-1639.

Walker, Donald E., Gregory R. Heath, and David A. Kubiak, 1998a. "Floatables control: Laboratory testing indicates underflow baffles hold promise." Water Environment and Technology, (published by the Water Environment Federation), February, 1998, pp. 45-48.

Walker, Donald E., Gregory R. Heath, and David A. Kubiak, 1998b. "CSO Floatables Control Using Underflow Baffles." Proceedings of the 1998 Water Environment Federation (WEF) Conference: Advances in Urban Wet Weather Pollution Reduction, Cleveland, Ohio. June 28 - July 1, 1998, pp. 665-671.

White, Dean K. and Johannes Larsen, 1997. "Hydraulic model study of typical CSO regulator structure." Prepared by Alden Research Laboratory, Inc. for Metcalf and Eddy and the Massachusetts Water Resources Authority, March 1997. 
